\title{
Cefaleia em Salvas Crônica responsiva a terapia combinada com Varfarina - Relato de caso
}

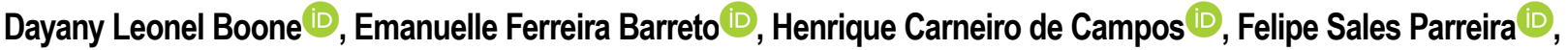 \\ Lucas Roquim e Silva
}

Santa Casa de Misericórdia de Belo Horizonte, Belo Horizonte, Minas Gerais, Brasil.

\begin{abstract}
Introdução
ZFA, sexo feminino, 55 anos, hipertensa e diabética, com histórico de migrânea sem aura desde a infância, com bom controle. Apresentou mudança do padrão das crises em 2014, descritas como cefaleia estritamente em hemicrânio esquerdo, forte intensidade, duração 1-2 horas, recorrente, 3-4 ataques/dia, associada a hiperemia conjuntival e congestão nasal ipsilateral. Exame neurológico e Ressonância magnética de encéfalo sem alterações. Realizado teste com indometacina, sem resposta. Tratamento agudo com sumatriptano nasal (boa resposta). Tentado tratamento profilático com diversas medicações, tais quais: prednisona e bloqueio do nervo occipital (boa resposta por curto período), verapamil(resposta parcial), Lítio (sem resposta), melatonina (pouca resposta), clomifeno (resposta parcial). Após refratariedade ao tratamento, optado por iniciar varfarina, com redução significativa das crises. Por último, iniciado Ácido Valpróico (boa resposta) mantendo 1 ataque a cada 2 meses.
\end{abstract}

\section{Objetivo}

Relatar um caso de cefaleia em salvas crônica.

\section{Material e métodos}

Revisão bibliográfica em comparação ao relato de caso.

\section{Resultados}

A cefaleia em salvas é a mais comum das cefaleias trigeminoautonômicas. Tem prevalência 4-15,6/100000 habitantes, preferencialmente homens adultos jovens. Pode ser episódica ou apresentar-se de forma crônica, com pouca remissão e alta refratariedade terapêutica. Houve necessidade de terapia combinada com várias drogas, sendo a Varfarina uma droga chave, com redução de mais de $50 \%$ no controle dos ataques. A Varfarina é indicada apenas nos casos refratários, tem ação como antagonista da vitamina $\mathrm{K}$ no metabolismo dos dendritos e neurônios, no ritmo circadiano do hipotálamo e na inflamação neurogênica do óxido nítrico.

\section{Conclusões}

A cefaleia em Salvas possui diagnóstico clínico peculiar, sendo cada vez melhor reconhecida e diagnosticada, sendo que o conhecimento e instituição do tratamento precocepode melhorar a qualidade de vida dos pacientes.

Palavras-chave: Cefaleia, Salvas, Crônica, Varfarina 